\title{
The Application of Discounted Cash Flow and Real Option Analysis Methods for Coal Mining Projects with Abandonment and Expansion Options: A Case Study of PT X in East Kalimantan, Indonesia
}

\author{
Efendi Sutrisno Departement of \\ Management Faculty of Economics \\ and Business Universitas Indonesia \\ Depok, Indonesia \\ efendisutrisno@yahoo.com
}

\author{
Eka Pria Anas Departement of \\ Management Faculty of Economics \\ and Business Universitas Indonesia \\ Depok, Indonesia \\ ekapanas@yahoo.com
}

\begin{abstract}
Recent rising coal prices starting in the second half of 2016 has motivated both existing coal companies and new players to dig deeper to expand their production capacities and to explore new sites. This exposes them to higher risks. A tool that not only quantifies business opportunities but also takes into account uncertainty in coal projects becomes crucial. The traditional valuation method of discounted cash flow (DCF) analysis has been used for very long time but it is not sufficient for mining because it does not capture the high uncertainty and operational flexibility in the industry. An alternative valuation method, real option (RO) analysis can complement the limitations of DCF. Most studies related to RO Analysis application in mining project have focused on coal price and mining cost volatilities, but none has examined the impact of foreign exchange rate volatility, especially the exchange rate between the US dollar (USD) and the Indonesian Rupiah (IDR) to the project value. This study aims to enrich the literature on RO analysis application using an Indonesian coal company as a case study. It shows that RO analysis improves decision making by taking into account uncertainty and management flexibility. Furthermore, this study examines how different volatilities impact project value. Besides price and cost volatilities studied previously, this study examines one additional parameter, the USD IDR exchange rate volatility, as well as how different option maturities affect project value. A case study analysis using quantitative method of project evaluation or capital budgeting is applied. Data are analyzed using descriptive and linear regression to form input parameters. First, DCF is applied; then, in order to capture uncertainty and management flexibility, RO Analysis is applied to complement the DCF method. This study confirms that RO Analysis improves decision making by accounting for uncertainty and management flexibility in the calculation. Volatility and option maturity are key parameters impacting the project value. The higher the volatility is, the higher the project value is. The longer the option life is, the higher the project value is.
\end{abstract}

Keywords-Real Option Analysis, Discounted Cash Flow, Project Evaluation, Capital Budgeting

\section{INTRODUCTION}

Coal has played an important role in human civilization for thousands of years; however, its importance became prominent during the industrial revolution. Coal is a popular energy source for power plants because its generation cost is lower than those of oil and gas. In fact, energy cost produced from coal is one-fifth that of gas and diesel [1].

Before the commodity boom in 2000, between 1900 and 2000 , coal consumption was in a steady state with an annual growth of $0.45 \%$. However, between 2000 and 2012, a commodity super cycle, driven by escalating economic growth in emerging markets, caused an increase in coal consumption with an annual growth rate of 4\% [2]. In 2016 alone, the Asia Pacific region had $74 \%$ of the total world coal consumption, led by China with $51 \%$ and India with $11 \%$ [2]. This consumption increase is reflected by the increase in coal prices. The Newcastle Coal Price (NEWC) Index, a widely used price benchmark for coal transactions showed that between 1988 and 2003, coal prices still hovered around 30 to 40 USD per MT. Notably however, it increased to 59 USD per MT in June 2004 and reached its peak price of 180 USD per MT in July 2008. This increase was reached within a short period of 4 years. However, in the global recession in 2008, the price of coal price went into free fall from its highest point to its lowest point of 49.82 USD per MT in January 2016. Then, starting in the second half of 2016 , the price of coal started to recover [3] to 106.78 USD per MT in January 2018 [4] as shown in Figure 1.

Even though recent coal demand has not increased substantially as seen during commodity boom era, the World Energy Council estimates that coal demand for electricity will still grow by $20 \%$ from 2013 to 2040 [5]. In addition, coal consumption for electricity generation in Indonesia is expected to increase from 82.2 million tons in 2017 to 179.8 million tons in 2027 [6]. In summary, the Indonesian coal industry has positive future prospects from both international and domestic markets.

Higher demand and sustained price will motivate both existing companies and new players to expand their production capacities and to aggressively explore new sites. This will expose them to higher risks. Runge [7] stated that mining industry is subject to uncertainties that are not applicable to other industries during both exploration and exploitation stages. A tool that can not only quantify business opportunity but also take into account uncertainty and flexibility becomes crucial. Many studies related to 
mining project evaluation agree that even though the discounted cash flow (DCF) method has been used to evaluate mining project for many years until today, it cannot capture the commodity uncertainty and operational flexibility characterizing mining projects [8]. A more comprehensive tool incorporating those unique characteristics needs to be considered. Real option (RO) analysis can complement the inherent shortages in DCF.

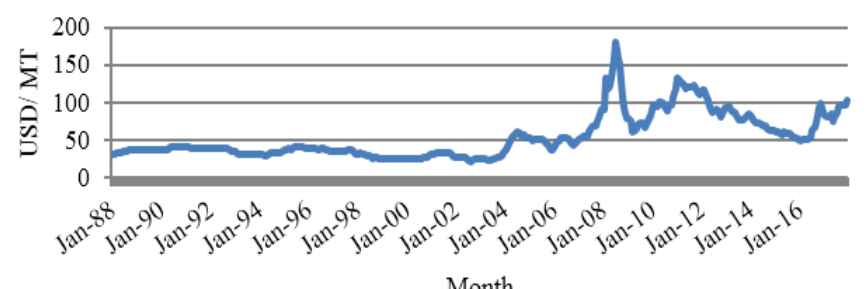

Fig. 1. NEWC index $1988-2017$

Many studies have been conducted using RO analysis. Research by Cruz Rambaud and Sánchez Pérez [9], Dehghani and Ataee-pour [10] and Haque et al. [11] showed that price and cost volatilities as well as option maturity impact project value. Haque et al. [11] admitted and suggested further study on foreign exchange volatility. Finally, Ampofo [12] found that the application of RO analysis was still restricted to research or academic purposes. Only about 14 to 17 percent of companies listed on the Toronto Stock Exchange (TSX) and U.S Fortune 1000 companies used $\mathrm{RO}$ analysis.

Despite Indonesia being the top coal exporter in the world, there are few studies related to applying RO analysis to Indonesian coal mining projects. Keeping in mind the uncertainty and management flexibility characterizing the mining industry, this study applies RO analysis to complement the DCF method and uses PT X as a case study. PT $X$ is a joint venture Indonesian company that has acquired several coal concessions in East Kalimantan.

Therefore, this study aims to enrich the literature on applying $\mathrm{RO}$ analysis to industries with uncertainty and management flexibility, like coal mining, to show that RO analysis improves decision making. Furthermore, this study will examine how different volatilities and option maturities impact project value. To close the gap, this study will examine one additional parameter, the exchange rate volatility between the US dollar and the Indonesian Rupiah (the USD IDR volatility), beyond the price and cost volatilities examined in most previous studies.

\section{LITERATURE REVIEW}

When facing a long-term project, a company needs to analyze, and then decide which projects to pursue. A valuation study is conducted to evaluate different potential projects. The International Valuation Standards Council [13] states that there are three main valuation approaches: the cost approach, the market approach, and the income approach. First, the cost approach assumes a buyer is not willing to pay higher than its cost to get the asset. There are three methods, which are the cost to replace, the cost to reproduce, and the cost to build $[13,14]$. The cost approach is usually used for assets that do not have a market, rare or are not traded [15]. Second, the market approach uses comparable multiples related to asset under study in order to estimate its market price. Common parameters used in the multiples are earnings, revenue or book value [13]. Third, the income approach utilizes a tool called the discounting process in which future forecasted cash flows of an asset are discounted to a present value at its cost of capital [13]. This is the most commonly used business valuation approach [15]. DCF and RO Analysis are examples of this approach.

DCF is calculated by discounting a project's future free cash flow (FCF) at its cost of capital over its forecasting period $[16,17]$. Even though DCF is one of the most widely used valuation methods, it has some drawbacks, which RO analysis tries to solve. Some RO Analysis methods are the Black Scholes Model (BSM) and the Binomial Lattice Model (BLM). The BLM is based on the formulation that an asset price can move either up or down in any time period. Therefore, if So is the current value of underlying asset, $\mathrm{Su}$ is the price moving up with probability $\mathrm{p}$ and $\mathrm{Sd}$ is the price moving down with probability $1-\mathrm{p}$. The general formulation of BLM is shown in Figure 2.

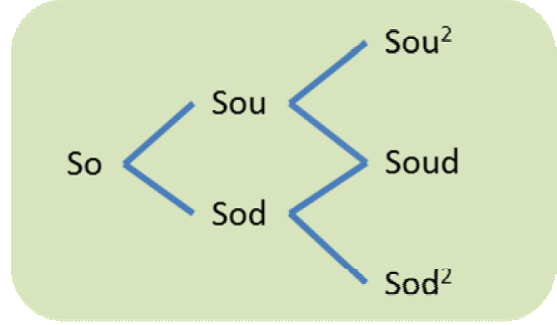

Fig. 2. BLM formulation

To calculate the option value using BLM, some input parameters - So, X, T, $\sigma$, and rf-need to be estimated. So is the PV of FCF under DCF. $X$ is the strike price or investment cost. $\mathrm{T}$ is the option maturity (in years) or how long the opportunity will still exist. $\sigma$ is the volatility or the uncertainty related to the cash flow of the underlying asset. The term rf is the riskless interest rate [18]. Based on these input parameters, the option parameters can be calculated as follows in Equations 1, 2, and 3.

$$
\begin{aligned}
& \mathrm{u}=\mathrm{e}^{\wedge}(\sigma \sqrt{ } \delta \mathrm{t}) \\
& \mathrm{d}=\mathrm{e}^{\wedge}(-\sigma \quad \sqrt{ } \delta \mathrm{t})=1 / \mathrm{u} \\
& \mathrm{p}=\left(\mathrm{e}^{\wedge}(\mathrm{rf})(\delta \mathrm{t})-\mathrm{d}\right) /(\mathrm{u}-\mathrm{d})
\end{aligned}
$$

where $\mathrm{p}$ represents risk-neutral probability, and $\mathrm{u}$ and $\mathrm{d}$ are asset up and asset down factors, respectively.

Most studies agree that RO analysis is the best tool to evaluate projects with high uncertainty or those that have embedded management flexibility. Evaluating mining projects without considering uncertainty may lead to future losses (or opportunities) and to invalid decision [10, 19]. Hall and Nicholls [20] point out that project value calculated using merely DCF usually produces values below the market value and $\mathrm{RO}$ analysis provides a formal approach to estimating this understated value. A study conducted by Ajak and Topal [19] that applies BLM with switching and expansion options on mining projects confirms the finding done Hall and Nicholls [20]. RO analysis has higher NPV compared to DCF since the model enables management to switch to a lower cost pit when the iron ore price declines and vice versa. In addition, a study by Cruz Rambaud and Sánchez Pérez [9] shows that option value (and thus project 
value) increases with respect to option maturity. The longer the option maturity is, the higher the value of the option is. Dehghani and Ataee-pour [10] point out that future metal prices and operating costs are the most important factors of uncertainty. Furthermore, according to Haque et al. [8], there is a strong relationship between commodity price volatility and project value. That study also suggests conducting further study on exchange rate volatility. Volatility represents the riskiness of the cash flow generated from a project. Culík [21] states that the formula for RO analysis is Expanded NPV = standard (static, passive) NPV under DCF + option value (active) under RO analysis.

\section{RESEARCH METHOD}

This study uses the quantitative method of project evaluation or capital budgeting, starting first with data collection. Next, data are analyzed to form the input parameters for financial forecasting and capital budgeting calculations. Then, DCF is used to evaluate the project. Finally, in order to capture uncertainty and flexibility, RO analysis is applied to complement DCF. The project value with flexibility is then calculated by summing the project value without flexibility under DCF method and then the option value using the RO analysis method. The diagram in Figure 3 summarizes the methodology used in the study.

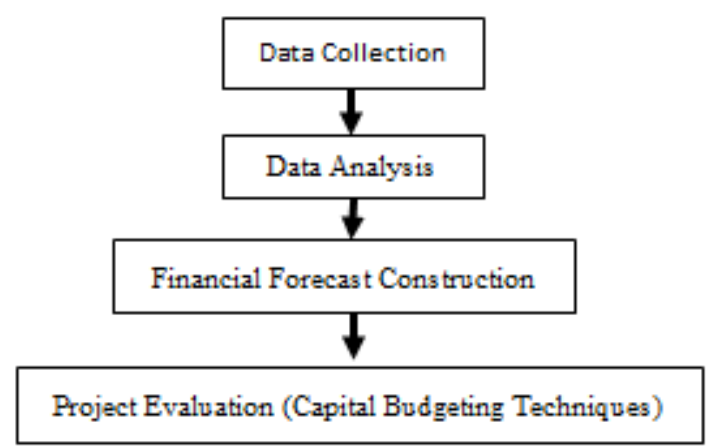

Fig. 3. Study methodology

\section{RESULT AND DISCUSSION}

This section examines not only the price (NEWC) and cost (Brent) volatilities, as most previous studies have done, but also one additional parameter, the USD IDR exchange rate volatility. The project value with flexibility will be computed by adding the project value without flexibility under DCF and the option value under RO analysis to show that RO analysis improves decision making. The hypothesis is that the project value for the Indonesian coal project (PT $\mathrm{X}$ ) should behave in a similar way as studies mentioned in the literature review: the higher the price volatility is, the higher the option value is $[8,10]$; similarly, the longer the option maturity is, the higher the option value is [9].

The cost of capital, the required rate of return shareholders expect for taking on a project, is computed using weighted cost of capital (WACC) [22]. To compute WACC, kd and ke need to be estimated, where kd equals to $5.6 \%$, the borrowing rate for national private banks [23]. Since interest payments are tax deductible, the after tax $\mathrm{k} \mathrm{d}=\mathrm{k} \mathrm{d} *(1-\operatorname{tax})$ is $(5.60 \% \mathrm{x}(1-25 \%))$ or $4.2 \%[22,24]$. The term $\mathrm{ke}$ is estimated using the formula proposed by Damodaran [25]: $\mathrm{ke}=\mathrm{rf}+\beta *$ equity risk premium.
The equity risk premium is calculated by the US country risk premium plus the Indonesian country risk premium. The equity risk premium is an additional return that a shareholder expects to receive for taking risk in excess of the riskless rate [25].

Three input parameters are needed to compute ke: rf, equity risk premium and $\beta$. First, rf equals $4.082 \%$, the tenyear USD Indonesian government bond rate [26]. Second, the mature market risk premium equals $5.08 \%$ and the country risk premium equals $2.54 \%$ [27]. Thus, the equity risk premium is $5.08 \%+2.54 \%$ or $7.62 \%$. Finally, Beta is estimated by conducting linear regression. The four biggest Indonesian coal companies in terms of market capitalization are PT Adaro Energy Tbk. (ADRO), PT Bukit Asam Tbk. (PTBA), PT Bayan Resources Tbk. (BYAN), and PT Indo Tambangraya Megah Tbk. (ITMG). These are assumed to represent the Indonesian coal industry. According to the single index model, $R_{-} i(t)=\alpha \_i+\beta \_(i) R \_M(t)+e \_(i)(t)$, $\beta_{-}(i)$ is the slope of the security line [28]. Regression results of those companies are shown in Figure 4.

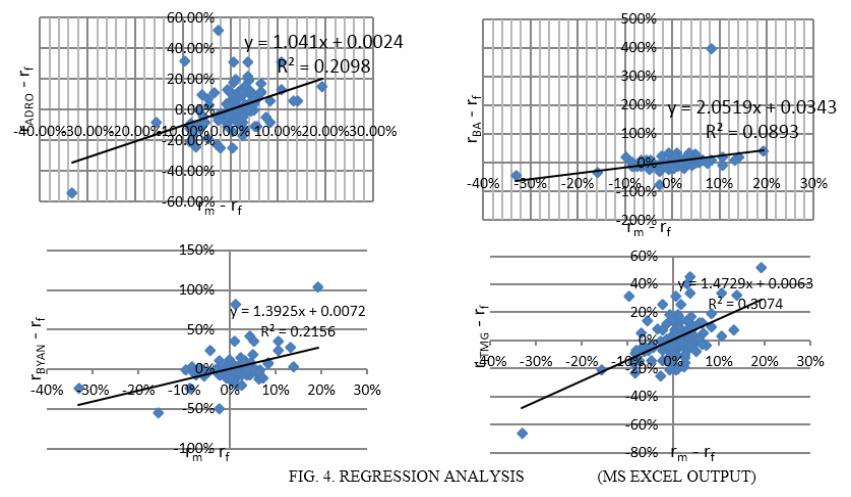

Fig. 4. Regression analysis

To find out the probability of the true value of beta, whether true $\beta$ is actually zero or not zero, significant slope testing needs to be conducted. The null and alternative hypotheses are Ho: $\beta=0$ and $\mathrm{H} 1: \beta \neq 0$. If the $p$ value $>$ $5 \%$, Ho: $\beta=0$ is accepted, meaning the true value of beta is zero with a $95 \%$ probability ( $95 \%$ level of confidence). If the $\mathrm{p}$ value $<5 \%$, Ho: $\beta=0$ is rejected, meaning the true value of beta is not zero. Thus, $\beta$ from regression analysis can be used as the $\beta$-estimate [28]. The resulting $p$ value test is shown in Table I below:

Since the $\mathrm{p}$ values for all four mining companies are less than $5 \%$, Ho: $\beta=0$ is rejected. The $\beta$ from the regression analysis can be used as the $\beta$-estimate for ke calculation. As shown in Table above, $\beta$ ADRO, $\beta$ PTBA, $\beta$ BYAN, and $\beta$ ITMG are $1.041,2.052,1.393$, and 1.473 , respectively. The $\beta$ measures the responsiveness of the company's share excess return relative to the movement in IDX excess returns [4, 29, 30]. Bodie et al. [28] and Damodaran [25] suggest that in order to minimize estimation error and since $\beta$ will be closer to 1 in the long run, $\beta$ needs to be adjusted. Thus, $\beta$-adjusted for ADRO, PTBA, BYAN, ITMG are 1.027, 1.701, 1,262, and 1.315 , respectively. Next, $\beta$ industry equals the (total (adjusted beta $\mathrm{x}$ equity) $/$ (total equity) or $7,004,526 / 5,940,135$, which is 1.179 . This signals that the Indonesian coal industry beta is quite close to $\beta_{-}$IDX 
$(\beta$ market $=1)$. Furthermore, since our $\beta$-estimate derives from $\beta$-company, which is affected by capital structure, its effect needs to be taken out. Thus, $\beta$ unleveraged $=$ $\beta$ equity/((1+(1-tax)Debt/Equity) $) \quad[22]$. The Debt to Equity $=$ Debt/Equity $=2,310 / 5,940=0.389$ and $\operatorname{Tax}=25 \%$; $\beta$ unleveraged equals $1.179 /\left(\left(1+(1-25 \%)^{*} 0.389\right)\right)$ or 0.913 . $\mathrm{k} \mathrm{e}=\mathrm{r} \mathrm{f}+\beta^{*}$ equity risk premium equals $4.082 \%+$ $0.913 * 7.62 \%$, or $11.04 \%$. Finally, WACC $=\mathrm{D} / \mathrm{V} \mathrm{k} \mathrm{d}(1-$ $\mathrm{Tax})+\mathrm{E} / \mathrm{V}$ k_e [8]. Since the project is fully funded by equity, $\mathrm{D} / \mathrm{V}=0 \%$ and $\mathrm{E} / \mathrm{V}$ equals $100 \%$, thus WACC equals ke or $11.04 \%$. The management has decided to use cost of capital (WACC) of $12 \%$.

For RO analysis, volatility is calculated by finding the annual standard deviation of the natural logarithm of the rate of return [31]. The statistical description of those volatilities is shown Table. II.

Since the annualized volatility is used for RO analysis, the resulting standard deviation needs to be annualized. The annualized volatility of NEWC, Brent, and USD IDR volatility are $24.50 \%, 40.00 \%$, and $11.44 \%$, respectively.
After the input parameters for financial forecasting have been formed, the third step is to construct a financial forecast [8]. The input parameters for financial forecasting are summarized as shown Table III.

TABLE I. BETA AND P VALUE TEST

\begin{tabular}{|c|c|c|c|c|}
\hline Company & Beta & pValue & Significant Test & Decision \\
\hline ADRO & 1.041 & 0.0000003 & $<5 \%$ & Reject Ho \\
\hline PTBA & 2.052 & 0.0012401 & $<5 \%$ & Reject Ho \\
\hline BYAN & 1.393 & 0.0000002 & $<5 \%$ & Reject Ho \\
\hline ITMG & 1.473 & 0.0000000 & $<5 \%$ & Reject Ho \\
\hline
\end{tabular}

TABLE II. STATISTICAL DESCRIPTIONS FOR VOLATILITIES

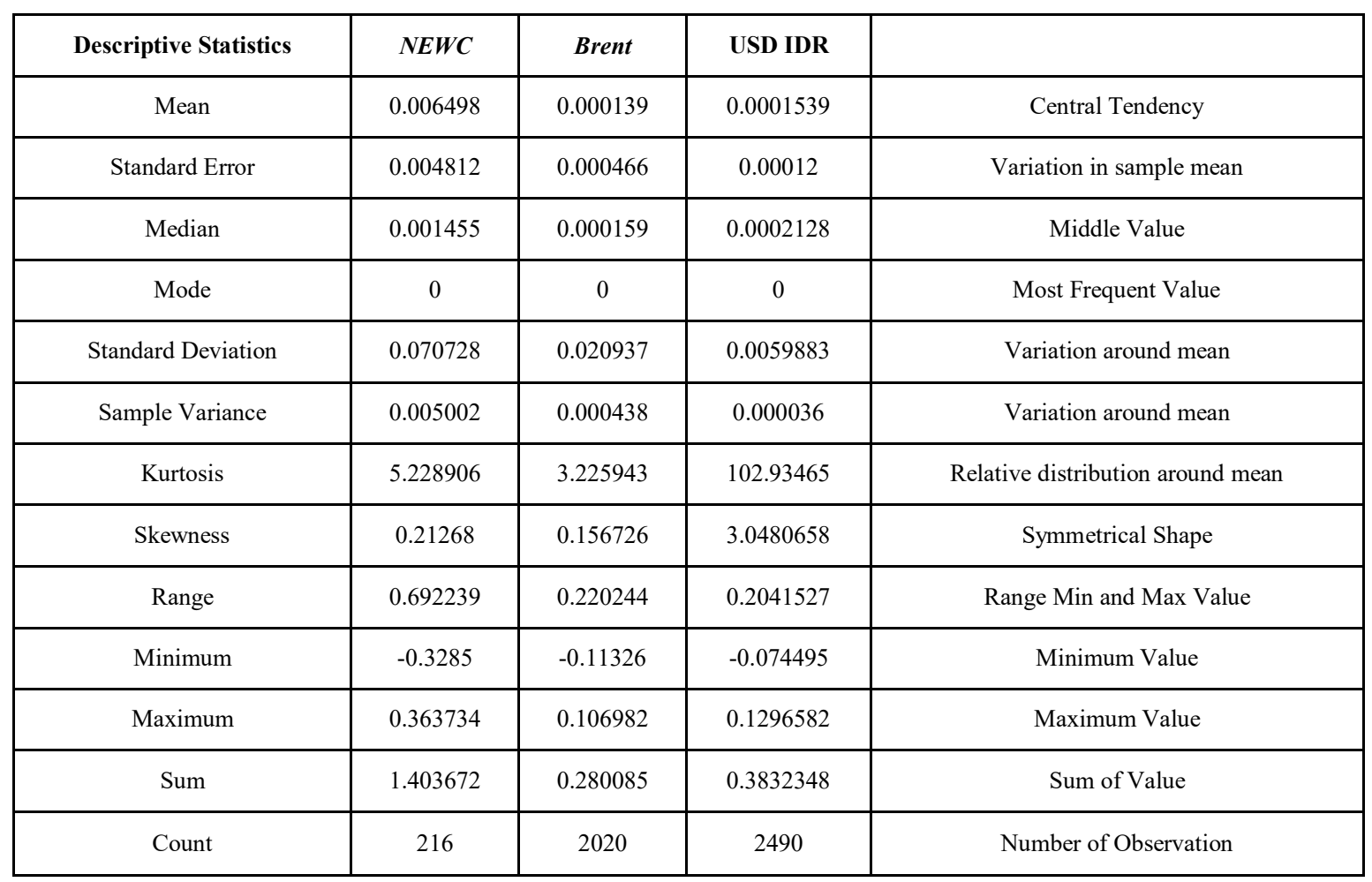

TABLE III. INPUT PARAMETERS FOR FINANCIAL FORECAST

\begin{tabular}{|l|l|}
\hline \multicolumn{1}{|c|}{ Variable } & \multicolumn{1}{c|}{ Value } \\
\hline Production volume (million tons) & 13.5 million tons \\
\hline coal price (USD per ton) & USD 80 \\
\hline Coal mining (USD per ton) & USD 66.44 \\
\hline Capital expenditure (million USD) & US\$ 43,68 (year 0) and USD 7,11 (year 1) \\
\hline
\end{tabular}


TABLE IV. Free CASH Flow (FCF) CALCUlations

\begin{tabular}{|l|c|c|c|c|c|c|c|c|c|c|c|}
\hline & $\mathbf{0}$ & $\mathbf{1}$ & $\mathbf{2}$ & $\mathbf{3}$ & $\mathbf{4}$ & $\mathbf{5}$ & $\mathbf{6}$ & $\mathbf{7}$ & $\mathbf{8}$ & $\mathbf{9}$ & $\mathbf{1 0}$ \\
& $\mathbf{2 0 1 8}$ & $\mathbf{2 0 1 9}$ & $\mathbf{2 0 2 0}$ & $\mathbf{2 0 2 1}$ & $\mathbf{2 0 2 2}$ & $\mathbf{2 0 2 3}$ & $\mathbf{2 0 2 4}$ & $\mathbf{2 0 2 5}$ & $\mathbf{2 0 2 6}$ & $\mathbf{2 0 2 7}$ & $\mathbf{2 0 2 8}$ \\
\hline EBITDA & -2.01 & 5.21 & 12.54 & 13.25 & 12.68 & 13.01 & 12.38 & 10.20 & 9.51 & 6.52 & -6.16 \\
EBIT & -2.01 & 1.06 & 8.46 & 9.18 & 8.61 & 8.94 & 8.31 & 6.12 & 5.60 & 2.76 & -7.42 \\
Tax on EBIT & 0.00 & 0.26 & 2.12 & 2.29 & 2.15 & 2.24 & 2.08 & 1.53 & 1.40 & 0.69 & 0.00 \\
\hline Gross Cash Flow & -2.01 & 4.95 & 10.43 & 10.95 & 10.53 & 10.78 & 10.31 & 8.67 & 8.11 & 5.83 & -6.16 \\
\hline Net change in working capital & 0.17 & -0.59 & -0.60 & -0.06 & 0.05 & -0.03 & 0.05 & 0.18 & 0.06 & 0.25 & 1.04 \\
& & & & & & & & & & & \\
Capital Expenditure & -43.68 & -7.11 & & & & & & & & \\
& & & & & & & & & & \\
\hline Free cash flow (FCF) & -45.52 & -2.75 & 9.82 & 10.90 & 10.58 & 10.75 & 10.36 & 8.85 & 8.17 & 6.07 & -5.12 \\
\hline Terminal Value & & & & & & & & & & & 26.82 \\
\hline Total FCF + TV & -45.52 & -2.75 & 9.82 & 10.90 & 10.58 & 10.75 & 10.36 & 8.85 & 8.17 & 6.07 & 21.70 \\
\hline
\end{tabular}

To apply DCF, the FCFs for the whole forecasting period and TV (terminal value) of the project need to be calculated as shown Table IV.

\section{A. Discounted Cash Flow}

The project value (NPV) is computed by adding $F$ of $\mathrm{FCF}=\sum_{t=0}\left[\frac{F C F_{t}}{\left(1+r^{2} t\right.}\right]$ plus

FV of $T V=\left[\frac{F C F_{n+1} /(r-g]}{\left[1+r^{3} n\right.}\right]$ at a discount rate equals to WACC [24, 32]. The result is that PT X's NPV equals 2.16 million USD. Alternatively, NPV can also be calculated by adding PV of inflow (expected cash flow) and PV of initial investment [31]. Thus, the NPV is 52.18-50.02, or 2.16 million USD. Both ways yield the same result. According to the decision rule, if the NPV is greater than zero, the project should be accepted $[22,33]$. However, since this project only yields a marginal NPV, there is a potential loss if the values in the assumptions change. Sensitivity analysis should be used to identify which variables affect the project value the most $[22,34]$.

\section{B. Sensitivity Analysis}

Sensitivity analysis on several input parameters is shown below:

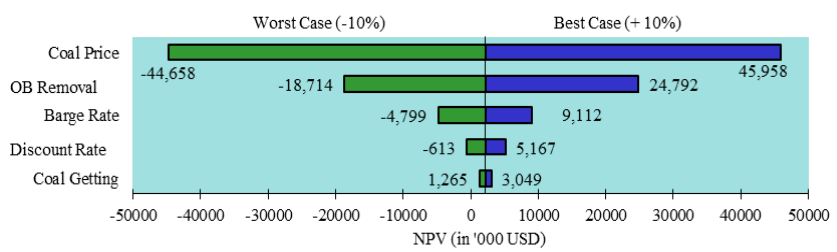

Fig. 5. Sensitivity analysis

The Tornado diagram shows that the project's NPV is very sensitive to the change in coal price, followed by the change in OB removal rate, since they have the widest NPV range. Coal price (NEWC) depends on the world's coal supply and demand, which are uncontrollable variables. Since revenue is in United States dollars (USD), while some costs are in Indonesian Rupiah, this project is also exposed to foreign exchange fluctuations. The OB removal rates are cost quoted by contractors, which are usually tied to fuel prices. If the (Brent) fuel price increases, those quoted price will also increase and vice versa. Thus, the impact on NEWC, Brent, and USD IDR exchange rate volatilities should be examined further with RO analysis.

\section{RO Analysis}

Two mutually exclusive simple option decisions: the abandonment option and the expansion option will be applied. RO analysis is calculated using the steps suggested by Kodukula and Papudesu [31]. To illustrate the calculation process, this section will only outline RO analysis for NEWC volatility, since the calculation for the other volatilities follows the same manner.

\section{Step 1: Framing the Application}

For the abandonment option, since the NPV result is marginal, there is a potential loss. The company has an option to abandon or to continue the project. The project can be sold at salvage value if the expected payoff of the underlying asset is less than the salvage value [31]. For the expansion option, because uncertainty is high, PT X may decide to begin partial operations with an option to expand. When the situation becomes clearer, PT X may expand its production. The expansion factor is 1.3 times with additional expansion costs (X) of 30.77 million USD. PT X will expand if the expected payoff of the underlying asset is greater than the strike price [31].

Step 2: Identifying the input parameters

The input parameters for the options to abandon and to expand are as follows.

TABLE V. INPUT PARAMTERS

\begin{tabular}{|l|l|l|}
\hline Input Parameter & $\begin{array}{l}\text { Option } \\
\text { to Abandon }\end{array}$ & $\begin{array}{l}\text { Option } \\
\text { to Expand }\end{array}$ \\
\hline $\begin{array}{l}\text { So (in million } \\
\text { USD) }\end{array}$ & 52.18 & 52.18 \\
\hline $\mathrm{X}$ (in million USD) & Vary & 30.77 \\
\hline Expansion Factor & $\mathrm{n} / \mathrm{a}$ & 1.30 \\
\hline $\mathrm{r}_{\mathrm{f}}$ & 0.0400 & 0.0400 \\
\hline$\sigma_{\mathrm{NEWC}}$ & 0.2450 & 0.2450 \\
\hline$\sigma_{\text {Brent }}$ & 0.4000 & 0.4000 \\
\hline$\sigma_{\mathrm{USD} / \mathrm{IDR}}$ & 0.1144 & 0.1144 \\
\hline $\mathrm{T}$ & 10 & 10 \\
\hline
\end{tabular}


As indicated in Table $\mathrm{V}$ above, the $\mathrm{X}$ for the abandonment option varies each year based on the remaining coal reserves value and fixed asset salvage value.

Step 3: Calculate the option parameters

Using formulas (1), (2) and (3) above, the option parameters are calculated as follows.

TABLE VI. INTERMEDIATE CALCULATIONS FOR BLM

\begin{tabular}{|c|c|}
\hline Option Parameters & Value \\
\hline$\Delta \mathrm{t}$ & 1.00 \\
\hline $\mathrm{U}$ & 1.2776 \\
\hline $\mathrm{D}$ & 0.7827 \\
\hline $\mathrm{P}$ & 0.5215 \\
\hline$(1-\mathrm{p})$ & 0.4785 \\
\hline
\end{tabular}

Step 4: Build the binomial tree and calculate the asset value at each node of the tree.

A binomial tree is built on a one-year time interval $(\delta \mathrm{t}=$ 1) over a 10-year period to expiration. The calculation is started at the very first node on the left (denoted by S0), which is equal to PV Expected Cash Flow under the DCF method (52.18 million USD). Then, moving to the second node $(\mathrm{t}=1)$, we multiply $\mathrm{S} 0$ by the up factor $(\mathrm{u}=1.2776)$ and the down factor $(\mathrm{d}=0.7827)$ to get 66.67 million USD (S0u $=52.18$ million USD $x$ 1.2776) and 40.84 million USD (S0d $=52.18$ million USD $\mathrm{x} 0.7827)$. The next nodes are calculated in the same way. The completed asset value at each node is as below

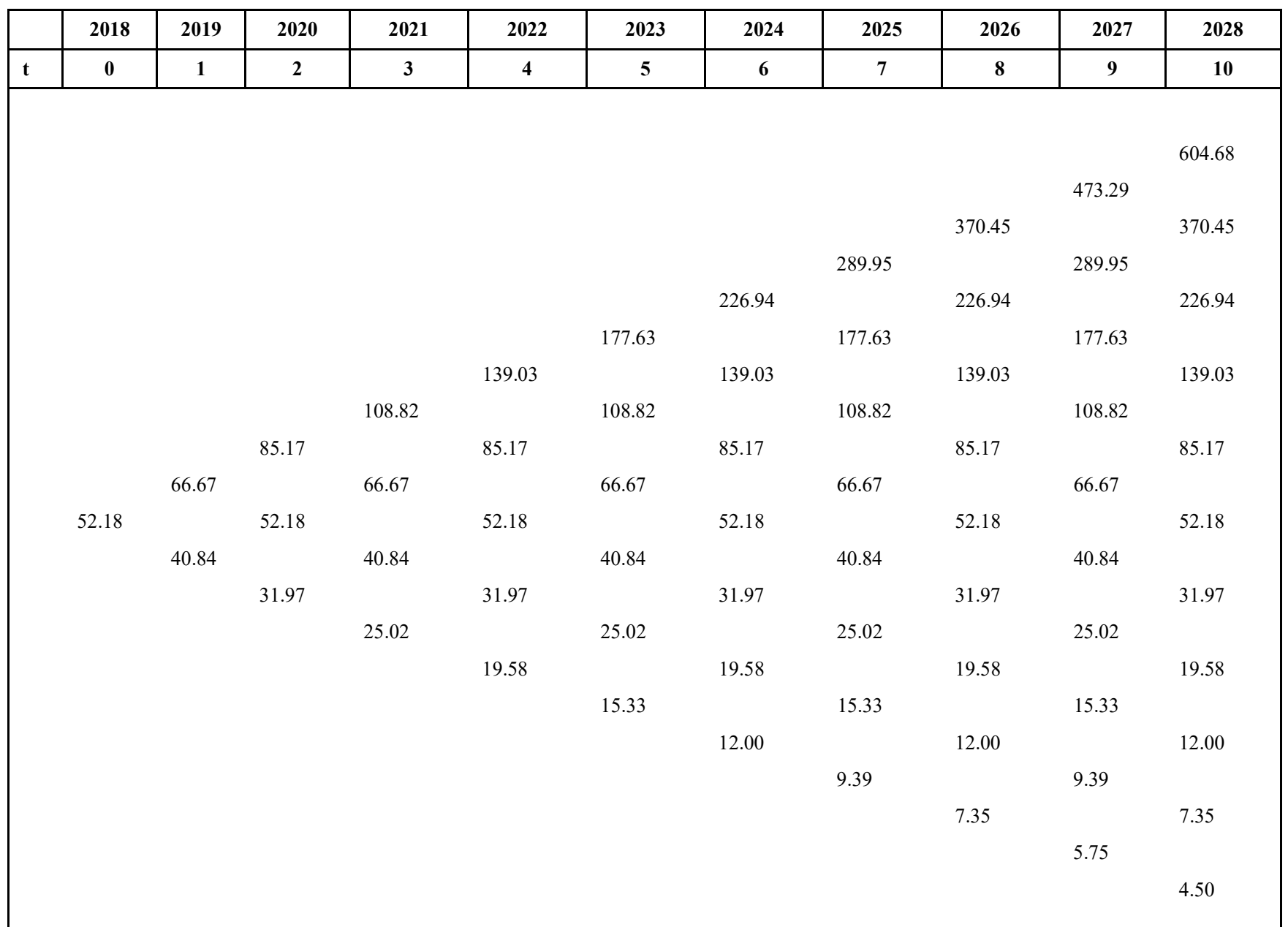

Fig. 6. Asset value for BLM

Step 5: Calculate the option values at each node of the tree by backward induction.

\section{Option to Abandon}

A decision is made at each node whether to abandon and to sell the project at the strike price (salvage value) or to continue the project and to keep the option opens, whichever has greater value. The calculation of the option value is started at the right side (at terminal node $t=10$ ). For example, in column 10 row 1 , the node is denoted as S0u10, the decision is whether to continue the project at asset value (S0u10), 604.68 million USD or to abandon at salvage value,
4.99 million USD. Since the objective is always to maximize the return, we choose to continue with the project so the option value equals 604.68 million USD.

To calculate the option value at intermediate nodes, the expected asset value for keeping the option open is calculated by discounting the weighted future option value using risk-neutral probability at the risk free rate [31]. To calculate the option value at column 9 row 1, the expected asset value for keeping the option open at node S0u9 is $[0.5215 \times 604.68+(1-0.52150) \times 370.45] \times \exp (-0.0400 \mathrm{x}$ $1.0)=473.29$ million USD. Since the objective is always to 
maximize the return between continuing the project at asset value (S0u9), 473.29 million USD or to abandon at salvage value, 6.55 million USD, we choose to continue the project and the option value equals 473.29 million USD. The calculation of other option value follows the same manner as above. At column 0, row 1, the option value of node S0 equals 55.78 million USD. The completed option value for NEWC volatility is as follows.

\begin{tabular}{|c|c|c|c|c|c|c|c|c|c|c|c|}
\hline & 2018 & 2018 & 2018 & 2018 & 2018 & 2018 & 2018 & 2018 & 2018 & 2018 & 2018 \\
\hline \multirow[t]{22}{*}{ t } & 0 & 1 & 2 & 3 & 4 & 5 & 6 & 7 & 8 & 9 & 10 \\
\hline & & & & & & & & & & & 604.68 \\
\hline & & & & & & & & & & 473.29 & \\
\hline & & & & & & & & & 370.45 & & 370.45 \\
\hline & & & & & & & & 289.95 & & 289.95 & \\
\hline & & & & & & & 226.94 & & 226.94 & & 226.94 \\
\hline & & & & & & 177.63 & & 177.63 & & 177.63 & \\
\hline & & & & & 139.03 & & 139.03 & & 139.03 & & 139.03 \\
\hline & & & & 108.82 & & 108.82 & & 108.82 & & 108.82 & \\
\hline & & & 85.17 & & 85.17 & & 85.17 & & 85.17 & & 85.17 \\
\hline & & 66.77 & & 66.67 & & 66.67 & & 66.67 & & 66.67 & \\
\hline & 55.78 & & 52.41 & & 52.18 & & 52.18 & & 52.18 & & 52.18 \\
\hline & & 48.55 & & 41.33 & & 40.84 & & 40.84 & & 40.84 & \\
\hline & & & 43.84 & & 33.04 & & 31.97 & & 31.97 & & 31.97 \\
\hline & & & & 38.43 & & 27.35 & & 25.02 & & 25.02 & \\
\hline & & & & & 33.02 & & 21.67 & & 19.58 & & 19.58 \\
\hline & & & & & & 27.35 & & 15.99 & & 15.33 & \\
\hline & & & & & & & 21.67 & & 12.00 & & 12.00 \\
\hline & & & & & & & & 15.99 & & 9.39 & \\
\hline & & & & & & & & & 10.44 & & 7.35 \\
\hline & & & & & & & & & & 6.55 & \\
\hline & & & & & & & & & & & 4.99 \\
\hline
\end{tabular}

Fig. 7. Option value for BLM - Abandonment option (NEWC)

\section{Option to Expand}

A decision is made at each node whether to expand the project by 1.3 times with additional cost of expansion of 30.77 million USD or to continue the project and to keep the option opens whichever has greater value.

The calculation of option value is started at right side (at terminal node $t=10$ ). At node S0u10, the decision is whether to continue the project as-is at asset value (S0u10), 604.68 million USD or to expand at 755.32 million USD (1.3 x 604.68 million USD-30.77 million USD). Since the objective is always to maximize the return, we choose to expand the project so the option value equals to 755.32 million USD. Next, at node S0u9, since the objective is always to maximize the return between continuing the project as-is at asset value (S0u9), 585.71 million USD $([0.5215 \times 755.32+(1-0.5215) \times 450.81] \mathrm{x} \exp (-0.0400 \mathrm{x}$ $1.0)$ ) or to expand at 584.51 million USD $(1.3 \times 473.29$ million USD -30.77 million USD), we choose to continue the project as-is so the option value equals 585.71 million USD. The calculation of other option values follows the same method as above. At column 0 , row 1, the option value of node S0 equals 55.49 million USD. The completed option value for NEWC volatility is as follows.

The above result supports the study results conducted by Haque et al. [11] and Dehghani and Ataee-pour [10] that volatility significantly impact project value. The higher the volatility is, the higher the option value is. Different option value results between BLM and BSM because BLM assumes various strike prices depending on project life while BSM assumes a fixed strike price throughout project life.

The project value with flexibility is calculated by adding project value without flexibility (under DCF) and option value calculated under either BLM or BSM. Project value without flexibility (under DCF) is 2.16 million USD. 


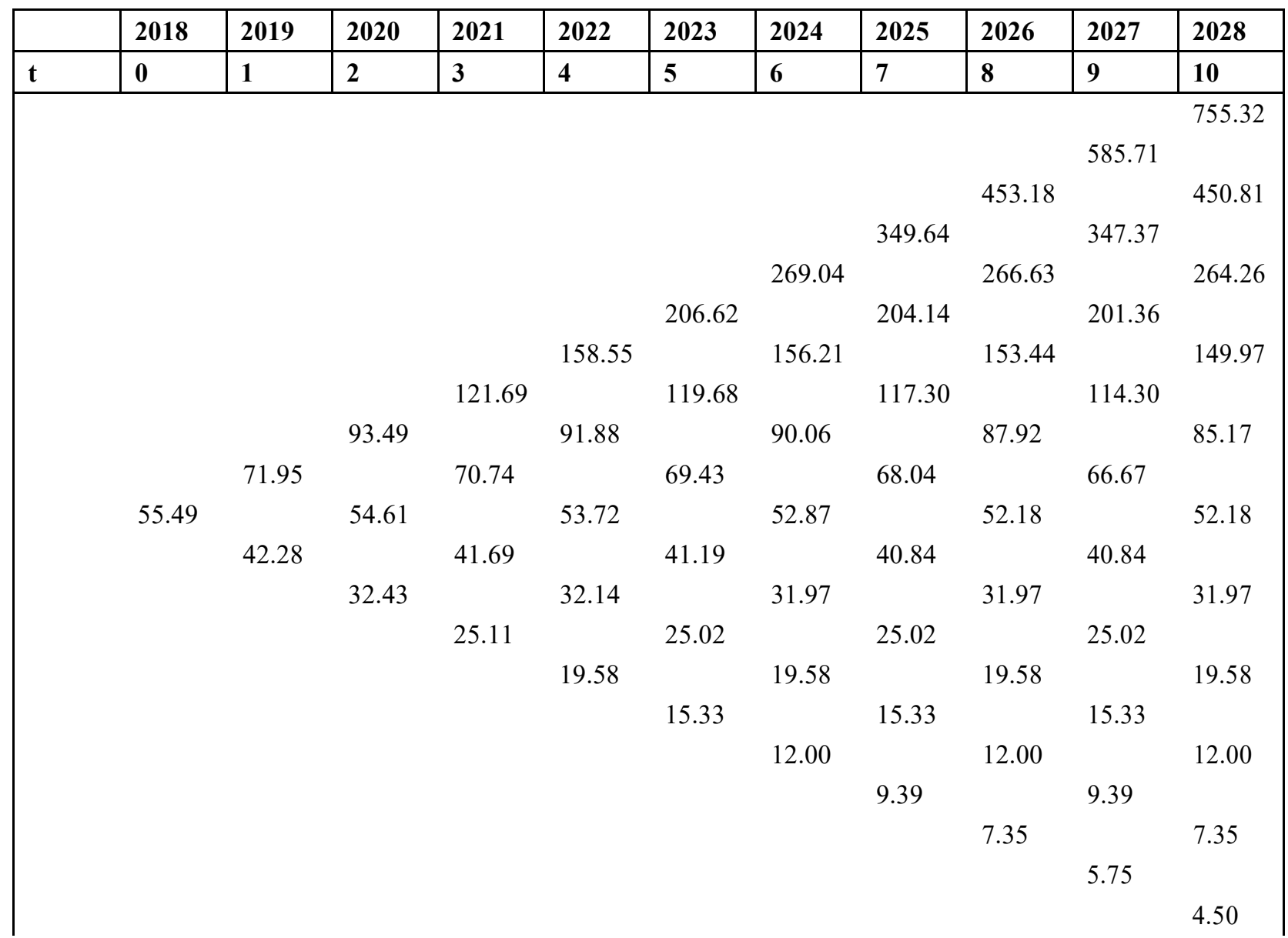

Fig. 8. Option value for BLM - Expansion option (NEWC)

Step 6: Analyze the result

The comparison of project value with flexibility for option to abandon is shown below:

\begin{tabular}{|l|c|c|c|c|c|c|c|}
\cline { 2 - 8 } & & \multicolumn{3}{c|}{ Binomial Lattice } & \multicolumn{3}{c|}{ Black Scholes } \\
\cline { 2 - 9 } & & NEWC & Brent & USD/IDR & NEWC & Brent & USD/IDR \\
\cline { 2 - 9 } Volatility & $\sigma$ & 0.2450 & 0.4000 & 0.1144 & 0.2450 & 0.4000 & 0.1144 \\
\hline Expiration Time (years) & $\mathrm{T}$ & 10 & 10 & 10 & 10 & 10 & 10 \\
\hline Strike Price (million USD) & $\mathrm{X}$ & Vary & Vary & Vary & 50.27 & 50.27 & 50.27 \\
\hline Asset Value at Expiration (million USD) & & 55.78 & 59.96 & 52.86 & & & \\
\hline Value Underlying Asset (million USD) & So & 52.18 & 52.18 & 52.18 & & & 12.09 \\
\hline Option Value & & 3.59 & 7.78 & 0.68 & 5.58 & & 0.83 \\
\hline NPV (DCF) - without flexibility & & 2.16 & 2.16 & 2.16 & 2.16 & 2.16 & 2.16 \\
\hline New Value - with flexibility & & 5.75 & 9.93 & 2.83 & 7.73 & 14.25 & 2.98 \\
\hline Probability of Abandon & & $0.1 \%$ & $5.5 \%$ & $0.0 \%$ & & & \\
\hline
\end{tabular}

Fig. 9. Comparison abandonment option for various volatility

Thus, project value with flexibility for NEWC, Brent and USD IDR volatility are 5.75 million, 9.93 million and 2.83 million USD, respectively under BLM and 7.73 million, 14.25 million and 2.98 million USD, respectively under BSM.

The possible number of paths for each node and the probability of the project being abandoned can be calculated using a Pascal triangle [31] and for $t=10$, there are total of $1,024\left(2^{\wedge} 10\right)$ possible paths. For the abandonment option, the project is abandoned when the strike price (salvage value) is greater than the expected asset value for keeping the option open. For NEWS volatility, there is only 1 possible path - the project being abandoned when the strike price (salvage value) equals 5 million USD (circled 
number). Dividing this number by the total possible paths $(1 / 1024)$ gives the probability that the project being abandoned for NEWC volatility, which equals $0.1 \%$. For Brent volatility, there are 56 possible paths $(1$ path +10 paths +45 paths) by which the project may be abandoned. Dividing 1,024 by 56 gives the probability of the project being abandoned for Brent volatility equal to $5.5 \%$. For USD IDR volatility, there are zero paths in which the project is abandoned. Thus, the probability of the project being abandoned for USD IDR volatility is $0 \%$. Furthermore, the probability of the project being continued (not abandoned) is calculated by subtracting the probability of being abandoned from one hundred percent. Hence, the probability that the project will be continued for NEWC, Brent, and USD IDR volatilities are $99 \%, 94.5 \%$, and $100 \%$ respectively. In short, there is a high chance that project $\mathrm{X}$ will be continued. The Pascal triangle for each volatility is shown in Figures 10, 11, and 12.

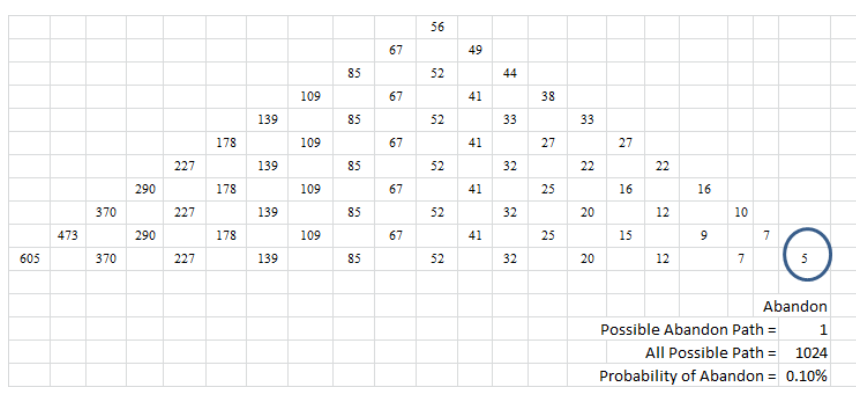

Fig, 10. Probability of abandon using pascal triangle (NEWC volatility)

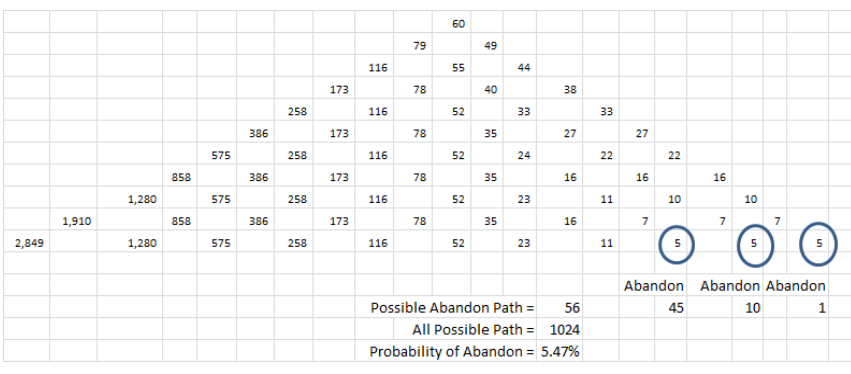

Fig. 11. Probability of abandon using pascal triangle (BRENT volatility)

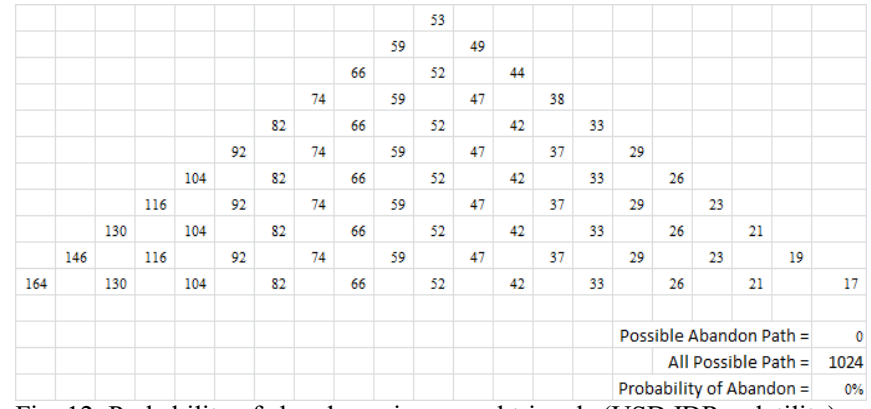

Fig. 12. Probability of abandon using pascal triangle (USD IDR volatility)

In addition, the comparison of project value for expansion option is shown Figure 13. Similar conclusions to the abandonment option can be drawn with the expansion option.

First, taking into account uncertainty and management flexibility, RO analysis improves decision making. Second, similar to abandonment option, the study also shows that the project value increases as volatility increases. Sensitivity analysis on different maturity option from 3 years to 10 years for expansion option is shown in the line charts below. Its result confirms the study result conducted by Cruz Rambaud and Sánchez Pérez [9] that concludes option value increases with respect to maturity option. However, the increase is not proportional since the gap between those lines get wider as option life increases as shown in Figure 14 and 15.

\section{CONCLUSION AND IMPLICATION}

In practice, management has the flexibility to alter its decisions based on prevailing conditions. When a commodity price is high, management may choose to expand its production and vice versa. Hence, RO analysis should be used to complement DCF. This study shows that by considering uncertainty (volatility) and management flexibility (abandonment and expansion options), RO analysis indeed improves decision making. A project that has high uncertainty will not be rejected prematurely. Moreover, this study also shows that volatility and option life are key parameters that impact project value. The higher the volatility is, the higher the project value is and the longer the option value is, the higher the project value is

\begin{tabular}{|c|c|c|c|c|c|c|c|}
\hline & & \multicolumn{3}{|c|}{ Binomial Lattice } & \multicolumn{3}{|c|}{ Black Scholes } \\
\hline & & NWC & Brent & US\$/IDR & NWC & Brent & US\$/IDR \\
\hline \multirow{5}{*}{$\begin{array}{l}\text { Volatity } \\
\text { Expiration Time (years) } \\
\text { Cost of Expansion (X) } \\
\text { Expansion Factor } \\
\text { Asset Value at Expiration (million US\$) }\end{array}$} & $\sigma$ & 0.2450 & 0.4000 & 0.1144 & 0.2450 & 0.4000 & 0.1144 \\
\hline & $\mathrm{T}$ & 10 & 10 & 10 & 10 & 10 & 10 \\
\hline & $\mathrm{X}$ & 30.77 & 30.77 & 30.77 & 30.77 & 30.77 & 30.77 \\
\hline & & 1.30 & 1.30 & 1.30 & 1.30 & 1.30 & 1.30 \\
\hline & & 55.49 & 58.38 & 52.79 & & & \\
\hline Value Underlying Asset (million USD\$) & So & 52.18 & 52.18 & 52.18 & & & \\
\hline Option Value (million US\$) & & 3.31 & 6.20 & 0.60 & 3.31 & 6.27 & 0.83 \\
\hline NPV (DCF) (million US\$) & & 2.16 & 2.16 & 2.16 & 2.16 & 2.16 & 2.16 \\
\hline New Value - with flexibility (million US\$) & & 5.46 & 8.36 & 2.76 & 5.46 & 8.43 & 2.98 \\
\hline
\end{tabular}

Fig. 13. Comparison expansion option for various volatility 


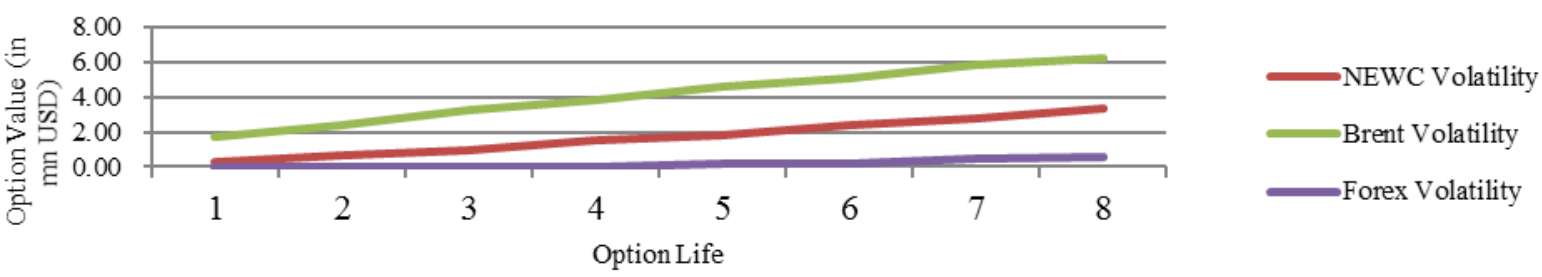

Fig. 14. Option value using BLM for various option lives

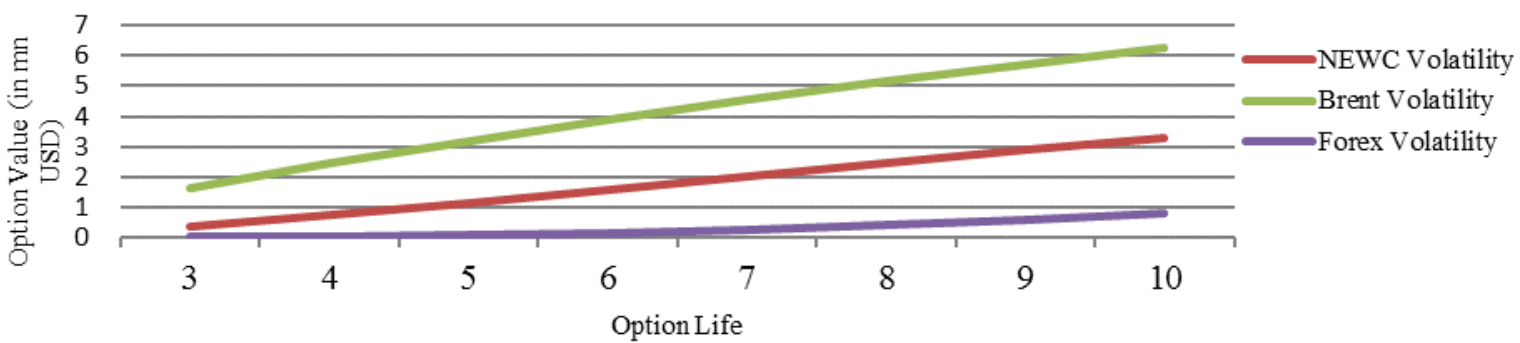

Fig. 15. Option value using BSM for various option lives

Since the probability of the project being abandoned is low, PT X should consider continuing the project as the situation becomes clearer. As PT X progresses with its exploitation, it may consider expanding its capacity, since the expansion option shows a potential upside. However, considering the option value for USD IDR volatility, the expansion may be done after year 5 , once the situation becomes clearer.

There are some limitations to the study, in that exploration on other concessions has not been completed, so there is no way to assure that the coal quality under the expansion option is exactly the same as the current quality. Furthermore, even though assumptions on mining costs have been verified with mining contractors, those values may change, depending on prevailing conditions, such as global coal demand and supply. To clear up the uncertainty, management could conduct either passive learning (do not do anything and let time resolve the uncertainty) or active learning (conduct further exploration or studies, market surveys or pilot projects to solve the uncertainty). If the result is promising, further expansion can be conducted in order to take advantage of the upside potential. To the contrary, if the result is not promising, the firm can scale down, continue the operation as-is, or even abandon the project to limit losses.

In addition to BLM and BSM methods, a Monte Carlo simulation could be applied to better estimate cost volatility using real historical operating costs. Thus, further study incorporating a Monte Carlo simulation to estimate volatility using real historical operating costs of similar coal project could be conducted to simulate the impact on the project value.

\section{REFERENCES}

[1] Indonesia Coal Mining Association. (2016). Indonesia Coal Industry Update 2016 (p. 24).

[2] Center for Energy Economics Research and Policy. (2017). BP Statistical Review of World Energy June 2017. London, U.K.

[3] Gandolphe, S. C. (2017). Indonesia' s Electricity Demand and the Coal Sector: Export or meet domestic demand? The Oxford Institute for Energy Studies, University of Oxford.
[4] Mundi Index. (2017). Australian Coal Price. Retrieved from https://www.indexmundi.com/commodities/

[5] World Energy Council. (2016). World Energy Resources 2016: Coal.

[6] Harlen. (2018). PLN 's Coal Demand Trend (p. 30).

[7] Runge, I. C. (1998). Mining Economics and Strategy. Society for Mining, Metallurgy, and Exploration, Inc.

[8] Haque, M. A., Topal, E., \& Lilford, E. (2014). A Numerical Study for a Mining Project Using Real Options Valuation Under Commodity Price Uncertainty. Resources Policy, 39, 115-123.

[9] Cruz Rambaud, S., \& Sánchez Pérez, A. M. (2017). The option to expand a project: its assessment with the binomial options pricing model. Operations Research Perspectives, 4, 12-20.

[10] Dehghani, H., \& Ataee-pour, M. (2012). Determination of the effect of operating cost uncertainty on mining project evaluation. Resources Policy, 37, 109-117.

[11] Haque, M. A., Topal, E., \& Lilford, E. (2014). A Numerical Study for a Mining Project Using Real Options Valuation Under Commodity Price Uncertainty. Resources Policy, 39, 115-123.

[12] Ampofo, K. D. (2017). Reasons why Real Options Analysis (ROA) is not widely adopted in the mineral industry. The University of Queensland.

[13] IVSC. (2017). International Valuation Standards (2011). IVSC.

[14] Mun, J. (2006). Real Options Analysis versus Traditional DCF Valuation in Layman's Terms.

[15] Turcas, F., Dumiter, F., Brezeanu, P., \& Jimon, S. (2016). Theoretical and Practical Issues in Business Valuation. Studia Universitatis Vasile Goldis Arad, Seria Stiintele Vietii, 26, 1-23.

[16] Bender, R. (2014). Corporate Financial Strategy (Fourth Edi). Routledge.

[17] Lander, D. M. (1997). Modeling and Valuing Real Option: An Influence Diagram Approach. University of Kansas.

[18] Kodukula, P., \& Papudesu, C. (2006). Project Valuation Using Real Options Analysis. J. Ross Publishing, Inc.

[19] Ajak, A. D., \& Topal, E. (2015). Real Option in Action: An Example of Flexible Decision Making at A Mine Operational Level. Resources Policy, 45, 109-120.

[20] Hall, J., \& Nicholls, S. (2007). Valuation of Mining Projects using Option Pricing Techniques. Finsia Journal of Applied Finance, (4), 22-30.

[21] Čulík, M. (2016). Real Options Valuation with Changing Volatility. Perspectives in Science, 7, 10-18.

[22] Ross, S. a, Westerfield, \& Jaffe. (2010). Corporate Finance, 9th Ed. (Ninth Edition). McGraw-Hill/ Irwin.

[23] Bank Indonesia. (2016). Indonesia Financial Statistics. 
[24] Copeland, T., Koller, T., \& Murrin, J. (2000). Valuation: Measuring and Managing the Value of Companies (Third). John Wiley \& Sons, Inc.

[25] Damodaran, A. (2002). Investment Valuation: Tools and Techniques for Determining the Value of Any Asset (Second Edi). John Wiley \& Sons, Inc, New York.

[26] Asian Development Bank. (2018). ID - USD Denominated Government Bond. Retrieved from https://asianbondsonline.adb.org/ indonesia/data/

[27] Damodaran, A. (2018). Country Default Spreads and Risk Premiums.

[28] Bodie, Z. (Boston U., Kane, A. (University of C., \& Marcus, A. J. Boston C. (2014). Investments. McGraw-Hill Education.

[29] Center for Energy Economics Research and Policy. (2017). BP Statistical Review of World Energy June 2017. London, U.K.
[30] Gandolphe, S. C. (2017). Indonesia' s Electricity Demand and the Coal Sector : Export or meet domestic demand? The Oxford Institute for Energy Studies, University of Oxford.

[31] Kodukula, P., \& Papudesu, C. (2006). Project Valuation Using Real Options Analysis. J. Ross Publishing, Inc.

[32] Haecker, C. U. (2000). Valuation of Internet Start-ups. California State University, Long Beach. https://doi.org/10.16953/deusbed. 74839

[33] Peterson, P. P., \& Fabozzi, F. J. P. D. (2002). Capital Budgeting: Theory and Practice. John Wiley \& Sons, Inc.

[34] Percoco, M., \& Borgonovo, E. (2012). A note on the sensitivity analysis of the internal rate of return. International Journal of Production Economics, 135, 526-529. 